
\title{
25 Research Soure \\ The Optimal Induction Timing In Prelabor Rupture of Membranes: A Retrospective Study
}

\section{Bachar Gal ( $\nabla$ gal.bachar13@gmail.com )}

Rambam Health Care Campus https://orcid.org/0000-0002-6290-2945

\section{Shemesh Doron}

Rambam Health Care Campus

\section{Farago Naama}

Rambam Health Care Campus

\section{Siegler Yoav}

Rambam Health Care Campus

\section{Lauterbach Roy}

Rambam Health Care Campus

Khatib Nizar

Rambam Health Care Campus

\section{Ginsberg Yuval}

Rambam Health Care Campus

\section{Beloosesky Ron}

Rambam Health Care Campus

\section{Weiner Zeev}

Rambam Health Care Campus

\section{Vitner Dana}

Rambam Health Care Campus

\section{Research Article}

Keywords: PROM, term, induction, time-to-delivery, chorioamnionitis.

Posted Date: February 7th, 2022

DOI: https://doi.org/10.21203/rs.3.rs-1073676/v1

License: (a) (i) This work is licensed under a Creative Commons Attribution 4.0 International License. Read Full License 


\section{Abstract}

Objective: Term prelabor rupture of membrane (PROM) occurs in $8 \%$ of term deliveries, but it is unclear when to initiate induction. Our objective was to assess the optimal timing of oxytocin induction in management of term PROM in terms of maternal and neonatal outcomes.

Methods: A retrospective cohort at a single tertiary care center from 2010 to 2020 . All singleton pregnancies with PROM beyond 37 weeks gestation, without regular uterine contractions, were included. Eligible women were divided into three groups according to the timing of oxytocin induction $(\leq 12 ; 12-24$; $\geq 24$ hours) following PROM.

Results: Of 9,443 women presented with term PROM, of them 1676 were included. They were classified according timing of oxytocin induction initiation following PROM: 1,127 within 12 hours; 285 within 12-24 hours; 264 after 24 hours. There were no significant differences in baseline demographic characteristics between groups. Women who were early induced delivered significantly sooner than those who received oxytocin later ( 45 vs. 28.2 vs. 23.2 hours, respectively, $p<0.001$. Maternal infection rate was similar and unrelated to oxytocin starting time. Their babies were less likely to receive antibiotics $(26.8 \%$ vs. $38.6 \%$ vs. $33.33 \%$, respectively; $p<0.001)$, and they had lower rates of composite adverse neonatal outcome $(\mathrm{RR}=1.27, \mathrm{p}=0.0307)$.

Conclusion: In term PROM, early induction (within 12 hours of PROM) may be recommended to reduce time-do-delivery interval and increase delivery rate within 24 hours. It may be of economic significance and improve women satisfaction. Furthermore, early induction may also improve neonatal outcomes, without worsening maternal outcomes.

\section{Introduction}

Prelabor rupture of the membranes (PROM) refers to rupture of the fetal membranes prior to the onset of regular uterine contractions[1]. Term PROM is referred to ruptured membranes beyond $37+0 / 7$ weeks of gestation. The frequency of term PROM in Unites States is estimated as $8 \%$ of pregnancies[2], [3]. Previous prospective studies have shown that $60 \%$ of these primiparous women with term PROM will deliver within 24 hours, and over $95 \%$ will begin delivery within 72 hours[4][5], [6]. These results are also consistent for women with an unfavorable cervix[7].

PROM at term can be managed actively by induction of labor or expectantly by waiting for the onset of a spontaneous contractions. Several studies have shown an association between expectant management and higher rates of maternal and neonatal adverse outcomes, especially infections[8], [9]. Furthermore, expectant management has been shown to increase the risk for cesarean delivery, cerebral palsy, neonatal chronic lung disease, and neonatal mortality[2], [5], [10]-[12]. It is suggested that the risk for those complications increases proportionally with the longer the duration of ruptured membranes[5], [13]. Others[7], [14] disagree with those associations. 
As a consequence, there are conflicting evidences which strategy is superior; active management versus expectant management. Candidates for expectant management include women with vertex presentation, reassuring fetal testing, no contraindications for vaginal delivery, and no signs or symptoms for infection. There are several methods for induction of labor when PROM, including oxytocin infusion, mechanical induction (balloon ripening) or chemical induction (prostaglandin E1/E2). In contrast to other indications for labor induction, there is no benefit for cervical ripening in PROM induction, compared with direct use of oxytocin, even in women with unfavorable cervix[15]-[17].

A recent Cochrane review[3] assessed maternal, fetal and neonatal effects of planned early birth when compared with expectant management for women with term PROM. Data from 23 randomized controlled trials, included 8615 women. The largest study in this review was conducted by Hannah et al in 1998[7] and included more than 5000 heterogeneous women (nulliparous and multiparous) who were randomized either for induction of labor (by either oxytocin or prostaglandins), or for expectant management (up to 4 days). They found a significant reduction in maternal infectious morbidity (clinical chorioamnionitis and endometritis) in women who were induced with oxytocin versus expectant management, with no difference in neonatal infection or CD rate between the groups[18]. As a result of that study, The Cochrane review was in favor of planned intervention following PROM at term[3]. However, most studies in that review were in poor quality, making those conclusions questionable. Additionally, the studies differed in parity, time of expectant management and mode of induction. According to The American College of Obstetricians and Gynecologists (ACOG, 2020), it is recommended to initiate delivery in case of term PROM, even when maternal and fetal status are reassuring. However, a short period (12-24 hours) of expectant management may be offered[19].

The aim of our study was to determine the optimal timing of oxytocin induction in term PROM, regardless of bishop score.

\section{Methods}

\section{Study Design and Population}

This was a retrospective cohort study of pregnant women admitted to labor and delivery unit with PROM beyond 37+0/7 weeks of gestation, in a university-affiliated medical centre between January 2010 and December 2020. The study was approved by the local Research Ethics Board (RMB-0017-20), waiving informed consent for de-identified patient information acquisition. Information collected from the hospital's database included access to the following variables: demographic information, medical history, obstetric history, and intrapartum and postpartum maternal-fetal variables.

Women presented with term PROM who received oxytocin induction were divided into three groups according to induction starting time: within 12 hours of membrane rupture (early group); between 12 to 24 hours of membrane rupture (intermediate group) and beyond 24 hours of membrane rupture (delayed group). Exclusion criteria included women who were in active labor or had regular contractions; women with contraindication for vaginal delivery, had a previous uterine scar, non-vertex presentation; non- 
reassuring fetal status, group B streptococcus colonization, or meconium fluid. We also excluded women who underwent expectant management.

The primary outcome of the study was defined as time from PROM to delivery. Maternal secondary outcomes included: infectious morbidity (fever> 38 degrees or uterine tenderness), mode of delivery, episiotomy rate, postpartum hemorrhage (PPH) rate, and total length of hospitalization following delivery. Prolonged hospitalization was defined as more than 2 days following vaginal delivery, or more than 5 days following CD. A composite of adverse maternal events consisted of one or more of the following: PPH, intrapartum fever, chorioamnionitis or endometritis.

Neonatal secondary outcomes included: Apgar score, rate of neonatal intensive care unit (NICU) admissions, antibiotic use, rates of cerebral palsy (CP), apnea, hypotonia, seizures and need for resuscitation. A composite of adverse neonatal events consisted of one or more of the following: Apgar score at 5 min $<7$, NICU admission, antibiotic administration, cerebral palsy, apnea, hypotonia, seizures and resuscitation.

\section{Statistical analyses}

Maternal and neonatal characteristics were compared using chi-squared test or Fisher exact test for categorical variables, whereas continuous variables were compared using ANOVA (or Kruskal-Wallis test). Pairwise comparisons were made using Chi-square test (or Fisher's exact test) for categorical variables, and t-test (or Wilcoxon rank sum test). Bonferroni correction was implemented to adjust for multiple comparisons. The statistical analysis was carried out using SAS 9.4 software (SAS Institute Inc., Cary, NC, USA). $\mathrm{P}<0.05$ was considered significant unless otherwise stated.

\section{Results}

The study included 9,443 women who were admitted to labor and delivery unit with ruptured membranes beyond 37 weeks of gestation. Of them, 1374 (14.5\%) were excluded due to previous caesarian delivery, $205(2.1 \%)$ due to non-vertex presentation, and 164 (1.7\%) due to group B streptococcus carrier status. Of the remaining 7,700 patients, 4,560 women were admitted with regular contractions in active labor. The final analysis included 3,140 women with PROM. Out of them, 1,464 had expectant management and 1,676 patients received oxytocin infusion: 1,127 within 12 hours of PROM; 285 between 12 to 24 hours of PROM and 264 more than 24 hours of PROM initiation (Figure 1).

Baseline characteristics are presented in Table 1. There were no significant differences in baseline characteristics among the three groups who received oxytocin, including age, parity, gestational week at delivery and medical and obstetric history (Table 1).

Delivery outcomes are details in Table 2. Early (within 12 hours of PROM) administration induction resulted in a shorter interval from membrane rupture to delivery, compared with intermediate (within 12-24 hours of PROM) and delayed oxytocin induction (>24 hours of PROM) administration (23.2 hours vs. 28.2 
hours vs. 45 hours, respectively, $\mathrm{p}<0.001)$. There were no differences in CS rates among groups, nor episiotomy and PPH. Intrapartum fever rate was similar between early, intermediate, and delayed groups $(5.68 \%$ vs. $7.37 \%$ vs. $4.92 \%$, respectively, $p>0.05)$. Other infectious variables (chorioamnionitis and endometritis) were also similar between all three groups ( $p>0.05)$. However, women receiving intermediate oxytocin infusion stayed longer in the hospital following their delivery compared with those who received early oxytocin induction (4 days vs. 3 days, $p=0.002$ ) (Table 2 ).

Newborn characteristics are presented in Table 3. Gender, birthweight and Apgar scores were similar between groups $(p>0.05)$. NICU admission rate was low in three groups, without significant differences. Yet, when mothers received early oxytocin induction, less newborns needed additional antibiotic treatment, compared with intermediate and delayed induction groups ( $26.8 \%$ vs. $38.6 \%$ vs. $33.33 \%$, respectively, $\mathrm{p}<0.001)$. Neonatal composite adverse outcome was less common in early oxytocin induction group, compared with intermediate and delayed groups $(27.42 \%$ vs. $38.95 \%$ vs. $34.47 \%$, respectively, $p<0.001)$. We performed a multivariable regression analysis after adjusting to confounding factors and found a significant reduction in neonatal composite adverse outcome with early oxytocin induction compared to intermediate oxytocin induction (RR 1.27, $p=0.0307$, Table 4).

\section{Discussion}

\section{$\underline{\text { Main findings }}$}

In this study, we evaluated maternal and neonatal adverse outcomes in women presented with prelabor rupture of membranes who received oxytocin induction. Women were divided to three groups according to oxytocin infusion beginning time. Our main findings were as follows: (1) Maternal infection rate was similar and unrelated to oxytocin starting time; (2) Women who were induced within 12 hours from ruptured membranes delivered sooner than those who received oxytocin later; (3) Newborns of mothers who received early oxytocin were less likely to receive antibiotics; (4) Composite adverse neonatal outcome was less prevalent with early oxytocin induction; (5) Early oxytocin induction shortened maternal hospital stay.

\section{Comparison with existing literature}

Previous studies presented maternal infectious morbidity rate ranging from 2-33\%, and as expected, the longer ruptured membrane duration, the higher infection rate[20]-[24]. However, those studies used variable definitions for maternal infectious morbidity (clinical diagnosis[23], fever[24], [25], leukocytosis[25], and more[21][22]). Furthermore, they compared oxytocin use versus expectant management and not different initiation time of oxytocin, so there is no data to support the optimal timing of induction in PROM. Hannah et al.[25], which investigated this topic and conducted the largest study to date, showed a significant increase in maternal infectious morbidity in the expectant management group compared to immediate induction group $(8.63 \%$ vs. $3.97 \%, R R=0.61, p<0.05)$ while waiting up to 4 days in the expectant management group. Other studies[21]-[24] did not find a significant difference in maternal infectious morbidity, although study populations were small (62-268 participants). 
Not showing a difference in maternal infectious rate in our cohort may be related to a small sample size, and a shorter duration for expectant management.

As may have been expected, women in the early induction group were more likely to deliver sooner, up to 23 hours on average from ruptured membranes, compared with intermediate and delayed induction groups (28 and 45 hours, respectively, $\mathrm{p}<0.001$ ). This is consistent with previous studies[24], [26]. Prolonged stay in labor and delivery unit may cause women and their partners to be frustrated and exhausted. Furthermore, women may be restricted to bed due to epidural analgesia. In overall, it may decrease their satisfaction and harm the whole birth experience.

Most studies[21], [24]-[26] correlate to ours with regards to antibiotic administration to newborns. The longer women waited to receive oxytocin, the higher the rate of neonate's antibiotic use. Undiagnosed and/or untreated sepsis can lead to neonatal mortality or long-term morbidity, and antibiotic treatment decrease these devastating outcomes. However, these drugs can exert unintended consequences, including disruption of the neonatal microbiota[27], [28] so they should be used with caution. If we can accomplish that by initiating oxytocin sooner (within 12 hours) rather than later, that should be taken into consideration while counseling patients with regards to induction versus expectant management, and timing of induction.

Neonatal adverse outcome (cerebral palsy, apnea, seizures etc.) in term PROM is known to be low[29][33], and likewise in our cohort. We found that babies of women who received oxytocin induction within 12 hours of PROM had lower rates of composite adverse outcome. Previous studies did not use a similar composite outcome, but isolated neonatal complications were low and similar between induction and expectant management groups[22], [25], [26], [34].

Our study presented a shorter median maternal hospitalization in the early oxytocin induction group, and so did Shalev et al. and Wagner et al.[22], [24] in their study. Length of hospitalization may pose a financial burden on the health care system, and it should also be considered when opting to induce women with PROM versus managing those women expectantly.

\section{Strengths and limitations}

Given the retrospective design of this study, some information was not available. Nonetheless, our study included a relatively large cohort of women with PROM who received oxytocin induction, demonstrating a different aspect of view and its potential effect on care provider management. This management may affect maternal and neonatal outcomes.

\section{Conclusions And Implications}

Our study demonstrates that early induction of Term PROM shortens time from PROM-to-Delivery, which can be responsible for a lower rate of antibiotics use for the neonates, lower adverse neonatal outcome and shorter maternal hospital stay. Additionally, there is an economic importance to those findings. We 
assume that shortening time to delivery may also influence maternal satisfaction, which should be examined in a prospective study.

\section{Declarations}

Conflict of Interest: The authors declare that they have no conflict of interest.

\section{Author Contribution}

G Bachar: Protocol/project development, Manuscript writing

D Shemesh: Data collection

N Farago: Data collection

Y Siegler: Data collection

R Lauterbach: Data collection

N Khatib: Data collection

Y Ginsberg: Data collection

R Beloosesky: Data collection

Z Weiner: management

D Vitner: Protocol/project development, Manuscript editing

\section{References}

[1] P. Duff, "Premature rupture of the membranes in term patients: Induction of labor versus expectant management," Clinical Obstetrics and Gynecology. 1998.

[2] H. Cammu, H. Verlaenen, and M. P. Derde, "Premature rupture of membranes at term in nulliparous women: A hazard?," Obstet. Gynecol., 1990.

[3] P. Middleton, E. Shepherd, V. Flenady, R. D. Mcbain, and C. A. Crowther, "Planned early birth versus expectant management (waiting) for prelabour rupture of membranes at term (37 weeks or more)," Cochrane Database of Systematic Reviews. 2017.

[4] D. I. Conway, W. J. Prendiville, A. Morris, D. C. E. Speller, and G. M. Stirrat, "Management of spontaneous rupture of the membranes in the absence of labor in primigravid women at term," $A m$. J. Obstet. Gynecol., 1984. 
[5] F. J. Zlatnik, "Management of premature rupture of membranes at term," Obstetrics and Gynecology Clinics of North America. 1992.

[6] G. C. Gunn, D. R. Mishell, and D. G. Morton, "Premature rupture of the fetal membranes. A review," American Journal of Obstetrics and Gynecology. 1970.

[7] M. E. Hannah and G. R. Seaward, "Prelabour rupture of membranes at term: The role of induction of labour," Fetal and Maternal Medicine Review. 1998.

[8] J. M. Alexander and S. M. Cox, "Clinical course of premature rupture of the membranes," Semin. Perinatol., 1996.

[9] A. S. Kong, S. J. Bates, and B. Rizk, "Rupture of membranes before the onset of spontaneous labour increases the likelihood of instrumental delivery," Br. J. Anaesth., 1992.

[10] R. Gonen, M. E. Hannah, and J. E. Milligan, “Does prolonged preterm premature rupture of the membranes predispose to abruptio placentae?," Obstet. Gynecol., 1989.

[11] G. B. Merenstein and L. E. Weisman, "Premature rupture of the membranes: Neonatal consequences," Semin. Perinatol., 1996.

[12] M. S. ROBSON, M. J. TURNER, J. M. STRONGE, and C. O'HERLIHY, "Is amniotic fluid quantitation of value in the diagnosis and conservative management of prelabour membrane rupture at term?", BJOG An Int. J. Obstet. Gynaecol., 1990.

[13] A. Gafni et al., "Induction of labour versus expectant management for prelabour rupture of the membranes at term: An economic evaluation," CMAJ, 1997.

[14] S. PG et al., "International Multicentre Term Prelabor Rupture of Membranes Study: evaluation of predictors of clinical chorioamnionitis and postpartum fever in patients with prelabor rupture of membranes at term.," in American journal of obstetrics and gynecology, 1997.

[15] B. P. Tan and M. Hannah, "Prostaglandins versus oxytocin for prelabour rupture of membranes at term," Cochrane Database Syst. Rev., 1997.

[16] G. J. Hofmeyr, A. M. Gülmezoglu, and C. Pileggi, "Vaginal misoprostol for cervical ripening and induction of labour," Cochrane Database Syst. Rev., 2010.

[17] M. G. Lin, F. S. Nuthalapaty, A. R. Carver, A. S. Case, and P. S. Ramsey, "Misoprostol for labor induction in women with term premature rupture of membranes: A meta-analysis," Obstetrics and Gynecology. 2005.

[18] R. Cecco, M. Hannah, E. Hodnett, G. Foster, D. Farine, and M. Helewa, "Prelabor rupture of the membranes (PROM) at term: expectant management at home vs in hospital," Am. J. Obstet. Gynecol., 
1998.

[19] “Prelabor Rupture of Membranes: ACOG Practice Bulletin, Number 217," Obstet. Gynecol., 2020.

[20] M. E. Hannah et al., "Induction of labor compared with expectant management for prelabor rupture of the membranes at term," N. Engl. J. Med., 1996.

[21] R. Natale, J. K. Milne, M. K. Campbell, P. G. G. Potts, K. Webster, and E. Halinda, "Management of premature rupture of membranes at term: Randomized trial," Am. J. Obstet. Gynecol., 1994.

[22] E. Shalev, D. Peleg, S. Eliyahu, and Z. Nahum, "Comparison of 12- and 72-Hour expectant management of premature rupture of membranes in term pregnancies," Obstet. Gynecol., 1995.

[23] L. S. Sperling et al., "Management of prelabor rupture of membranes at term: A randomized study," Acta Obstet. Gynecol. Scand., 1993.

[24] M. V. Wagner, V. P. Chin, C. J. Peters, B. Drexler, and L. A. Newman, "A comparison of early and delayed induction of labor with spontaneous rupture of membranes at term," Obstet. Gynecol., 1989.

[25] M. E. Hannah et al., "Induction of Labor Compared With Expectant Management for Prelabor Rupture of the Membranes at Term," Obstet. Gynecol. Surv., 1996.

[26] A. D., M. T., U. A., and Y. K., "Prelabour rupture of the membranes at term - No advantage of delaying induction for 24 hours," Aust. New Zeal. J. Obstet. Gynaecol., 1999.

[27] C. T. Peterson, V. Sharma, L. Elmén, and S. N. Peterson, "Immune homeostasis, dysbiosis and therapeutic modulation of the gut microbiota," Clinical and Experimental Immunology. 2015.

[28] M. Laws, A. Shaaban, and K. M. Rahman, "Antibiotic resistance breakers: Current approaches and future directions," FEMS Microbiology Reviews. 2019.

[29] M. Oskoui, F. Coutinho, J. Dykeman, N. Jetté, and T. Pringsheim, "An update on the prevalence of cerebral palsy: A systematic review and meta-analysis," Developmental Medicine and Child Neurology. 2013.

[30] M. Hirvonen et al., "Cerebral palsy among children born moderately and late preterm," Pediatrics, 2014.

[31] D. J. HENDERSON-SMART, "The effect of gestational age on the incidence and duration of recurrent apnoea in newborn babies," J. Paediatr. Child Health, 1981.

[32] C. Amiel-Tison, F. Maillard, F. Lebrun, G. Bréart, and E. Papiernik, "Neurological and physical maturation in normal growth singletons from 37 to 41 weeks' gestation," Early Hum. Dev., 1999. 
[33] H. C. Glass, T. N. Pham, B. Danielsen, D. Towner, D. Glidden, and Y. W. Wu, "Antenatal and Intrapartum Risk Factors for Seizures in Term Newborns: A Population-Based Study, California 19982002," J. Pediatr., 2009.

[34] H. P. Ottervanger, M. J. N. C. Keirse, W. Smit, and J. P. Holm, "Controlled comparison of induction versus expectant care for prelabor rupture of the membranes at term," J. Perinat. Med., 1996.

\section{Tables}

Table 1. Maternal baseline characteristics, by oxytocin administration timing

\begin{tabular}{|c|c|c|c|c|}
\hline & $\begin{array}{l}0-12 \text { hours } \\
\text { following } \\
\text { PROM }\end{array}$ & $\begin{array}{l}12-24 \text { hours } \\
\text { following PROM } \\
\mathrm{N}=285\end{array}$ & $\begin{array}{l}\text { 24+ hours following } \\
\text { PROM } \\
\text { N=264 }\end{array}$ & $\begin{array}{l}\mathrm{P} \text { - } \\
\text { value }\end{array}$ \\
\hline & \multicolumn{4}{|l|}{$N=1127$} \\
\hline Age, y & $\begin{array}{l}29.7[18.1- \\
46.7]\end{array}$ & $29.4[18.2-44.6]$ & $28.7[18.8-47.8]$ & NS \\
\hline \multicolumn{4}{|l|}{ Ethnicity } & \multirow[t]{6}{*}{ NS } \\
\hline Jewish & 788 & $193(67.72 \%)$ & $174(65.91 \%)$ & \\
\hline Muslim & $(09.9210)$ & $52(18.25 \%)$ & $62(23.48 \%)$ & \\
\hline Christian & $\begin{array}{l}198 \\
(17.57 \%)\end{array}$ & $10(3.51 \%)$ & $9(3.41 \%)$ & \\
\hline \multirow[t]{2}{*}{ Other } & $41(3.64 \%)$ & $30(10.52 \%)$ & $19(7.20 \%)$ & \\
\hline & $100(8.87 \%)$ & & & \\
\hline Parity, n [range] & $1.8[1-11]$ & $1.6[1-9]$ & $1.5[1,1-6]$ & NS \\
\hline $\begin{array}{l}\text { Gestational age at delivery, } \mathrm{n} \\
\text { [range] }\end{array}$ & $\begin{array}{l}39.2[37- \\
43.3]\end{array}$ & $39.2[37-42.2]$ & $39.3[37-41.5]$ & NS \\
\hline Background diseases, n (\%) & & & & NS \\
\hline Hypertension & $10(0.89 \%)$ & $5(1.75 \%)$ & $2(0.76 \%)$ & \\
\hline Diabetes & $86(7.63 \%)$ & $16(5.61 \%)$ & $19(7.2 \%)$ & \\
\hline Smoking & 13 (1.15\%) & 1 (0.35\%) & 3 (1.14\%) & \\
\hline
\end{tabular}

Data are presented as mean \pm SD or $n(\%)$ or $n$ [range]; PROM=prelabor rupture of membranes; NS=no significance

Table 2. Delivery outcomes, by oxytocin administration timing 


\begin{tabular}{|c|c|c|c|c|}
\hline & $\begin{array}{l}0-12 \text { hours } \\
\text { following } \\
\text { PROM } \\
\mathrm{N}=1127\end{array}$ & $\begin{array}{l}12-24 \text { hours } \\
\text { following PROM } \\
\mathrm{N}=285\end{array}$ & $\begin{array}{l}24+\text { hours } \\
\text { following PROM } \\
\mathrm{N}=264\end{array}$ & P-value \\
\hline $\begin{array}{l}\text { Interval from membrane } \\
\text { rupture to delivery, hours, mean } \\
\text { [range] }\end{array}$ & $23.2[8-80]$ & $28.2[12.2-61.4]$ & 45 [25.8-78] & $\begin{array}{l}*<.0001 \\
* *<.0001 \\
* * * \\
<.0001\end{array}$ \\
\hline Delivery mode, $\mathrm{n}(\%)$ & & & & NS \\
\hline $\begin{array}{l}\text { Spontaneous } \\
\text { Cesarean } \\
\text { Vacuum/Forceps }\end{array}$ & $\begin{array}{l}809 \\
(71.78 \%) \\
174 \\
(15.44 \%)\end{array}$ & $\begin{array}{l}194(68.07 \%) \\
42(14.74 \%) \\
49(17.19 \%)\end{array}$ & $\begin{array}{l}188(71.21 \%) \\
31(11.74 \%) \\
45(17.05 \%)\end{array}$ & \\
\hline & $\begin{array}{l}144 \\
(12.78 \%)\end{array}$ & & & \\
\hline Episiotomy, n (\%) & $\begin{array}{l}340 \\
(30.17 \%)\end{array}$ & $103(36.14 \%)$ & $92(34.85 \%)$ & NS \\
\hline PPH, n (\%) & $23(2.04 \%)$ & $9(3.16 \%)$ & $12(4.55 \%)$ & NS \\
\hline Intrapartum fever, n (\%) & $64(5.68 \%)$ & $21(7.37 \%)$ & $13(4.92 \%)$ & NS \\
\hline $\begin{array}{l}\text { Days of hospitalization, mean } \\
\text { [median, range] }\end{array}$ & $\begin{array}{l}3.5[3,1- \\
17]\end{array}$ & $3.7[4,2-9]$ & $3.6[3,1-7]$ & 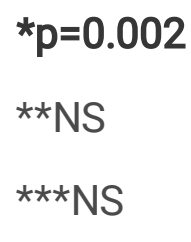 \\
\hline $\begin{array}{l}\text { Maternal composite outcome }{ }^{+} \text {, } \\
\text { n (\%) }\end{array}$ & $66(5.86 \%)$ & $21(7.37 \%)$ & $14(5.3 \%)$ & NS \\
\hline
\end{tabular}

Data are presented as mean \pm SD or $\mathrm{n}(\%)$ or $\mathrm{n}$ [range]; PROM=prelabor rupture of membranes; $\mathrm{NS}=\mathrm{no}$ significance; $\mathrm{PPH}=$ postpartum hemorrhage.

* Comparison between $0-12 \mathrm{~h}$ group to $12-24 \mathrm{~h}$ group.

** Comparison between $0-12 \mathrm{~h}$ group to $24 \mathrm{~h}+$ group.

$\star \star \star *$ Comparison between $12-24 \mathrm{~h}$ group to $24 \mathrm{~h}+$ group.

${ }^{+}$Maternal composite outcome included one of the following: PPH, intrapartum fever, chorioamnionitis, endometritis.

Table 3. Newborn characteristics and outcomes, by oxytocin intake 


\begin{tabular}{|c|c|c|c|c|}
\hline & $\begin{array}{l}0-12 \text { hours } \\
\text { following } \\
\text { PROM }\end{array}$ & $\begin{array}{l}12-24 \text { hours } \\
\text { following PROM } \\
\mathrm{N}=285\end{array}$ & $\begin{array}{l}\text { 24+ hours following } \\
\text { PROM } \\
\text { N=264 }\end{array}$ & $\begin{array}{l}\mathrm{P}- \\
\text { value }\end{array}$ \\
\hline & $\mathrm{N}=1127$ & & & \\
\hline Gender - male, n (\%) & $591(52.44 \%)$ & $140(49.12 \%)$ & $141(53.41 \%)$ & NS \\
\hline Weight, g, mean [range] & $\begin{array}{l}3245.2[1899- \\
4715]\end{array}$ & $\begin{array}{l}3256.3[2200- \\
4505]\end{array}$ & 3229 [2130-4400] & NS \\
\hline Apgar score & & & & NS \\
\hline $1 \mathrm{~min}$ & $8.7[1-10]$ & $8.6[1-10]$ & $8.8[2-10]$ & \\
\hline $5 \mathrm{~min}$ & $9.8[4-10]$ & $9.8[4-10]$ & $9.9[7-10]$ & \\
\hline NICU admission, n (\%) & $4(0.35 \%)$ & $0(0 \%)$ & $3(1.14 \%)$ & NS \\
\hline $\begin{array}{l}\text { Antibiotic administration, } \mathrm{n} \\
(\%)\end{array}$ & $302(26.8 \%)$ & $110(38.6 \%)$ & $88(33.33 \%)$ & $\begin{array}{l}* \\
<.0001 \\
* * \text { NS } \\
* * * \text { NS }\end{array}$ \\
\hline Complications, n (\%) & & & & NS \\
\hline $\mathrm{CP}$ & $0(0 \%)$ & $0(0 \%)$ & $0(0 \%)$ & \\
\hline Apnea & $3(0.27 \%)$ & $0(0 \%)$ & $0(0 \%)$ & \\
\hline Hypotonia & $1(0.09 \%)$ & $0(0 \%)$ & $0(0 \%)$ & \\
\hline Seizures & $2(0.18 \%)$ & $1(0.35 \%)$ & $0(0 \%)$ & \\
\hline Resuscitation & $1(0.09 \%)$ & $0(0 \%)$ & $0(0 \%)$ & \\
\hline $\begin{array}{l}\text { Neonatal composite } \\
\text { outcome }^{+}, \mathrm{n}(\%)\end{array}$ & $309(27.42 \%)$ & $111(38.95 \%)$ & $91(34.47 \%)$ & $\begin{array}{l}* \\
<.0001 \\
* \star N S \\
* * * \text { NS }\end{array}$ \\
\hline $\begin{array}{l}\text { Days of hospitalization, } \\
\text { mean [range] }\end{array}$ & $3.2[1.4-23.4]$ & $3.2[1.6-16.9]$ & $3.2[1.8-12.4]$ & NS \\
\hline
\end{tabular}

Data are presented as mean \pm SD or $\mathrm{n}(\%)$ or $\mathrm{n}$ [range]; PROM=prelabor rupture of membranes; $\mathrm{NS}=\mathrm{no}$ significance.

* Comparison between 0-12h group to $12-24 \mathrm{~h}$ group.

** Cmparison between $0-12 \mathrm{~h}$ group to $24 \mathrm{~h}+$ group.

*** Comparison between $12-24 \mathrm{~h}$ group to $24 \mathrm{~h}+$ group. 
${ }^{+}$Neonatal composite outcome includes one of the following - Apgar score at 5 min $<7$, NICU admission, antibiotic administration, cerebral palsy, apnea, hypotonia, seizures, resuscitation.

Table 4- Multivariable log-binomial regression for the study outcomes

Multivariable regression

$\begin{array}{lll}\text { Adj. RR } & 95 \% \mathrm{Cl} & \text { P-value } \\ \text { Low Up } & \end{array}$

Maternal composite outcome ${ }^{+}$

\begin{tabular}{lllll}
\hline Age $\geq 35$ & 1.04 & 0.66 & 1.63 & 0.8683 \\
\hline Interval from membrane & 1.016 & 1.011 & 1.021 & $<.0001$ \\
rupture to delivery & & & & \\
\hline
\end{tabular}

Oxytocin

\begin{tabular}{lllll}
\hline Oxytocin 0-12 h after PROM & 1 & & & \\
\hline Oxytocin 12-24 h after PROM & 1.07 & 0.65 & 1.75 & 0.7876 \\
\hline Oxytocin 24+ h after PROM & 0.43 & 0.23 & 0.81 & 0.0086 \\
\hline
\end{tabular}

\begin{tabular}{lllll|}
\hline Neonatal composite outcome & \\
& & & & \\
\hline Age $\geq 35$ & 1.00 & 0.82 & 1.22 & 0.9982 \\
\hline $\begin{array}{l}\text { Interval from membrane } \\
\text { rupture to delivery }\end{array}$ & 1.024 & 1.019 & 1.028 & $<.0001$ \\
\hline
\end{tabular}

\section{Oxytocin}

Oxytocin 0-12 h after PROM 1

\begin{tabular}{lllll} 
Oxytocin 12-24 h after PROM & $\mathbf{1 . 2 7}$ & 1.02 & 1.58 & $\mathbf{0 . 0 3 0 7}$ \\
\hline Oxytocin 24+ h after PROM & 0.78 & 0.60 & 1.02 & 0.0716
\end{tabular}

Data are presented as mean $\pm \mathrm{SD}$ or $\mathrm{n}(\%)$ or $\mathrm{n}$ [range]; PROM=prelabor rupture of membranes; $\mathrm{Adj}$. RR= adjusted relative risk.

${ }^{+}$Maternal composite outcome includes one of the following - PPH, intrapartum fever, chorioamnionitis or endometritis.

${ }^{++}$Neonatal composite outcome includes one of the following - Apgar score at 5 min $<7$, NICU admission, antibiotic administration, cerebral palsy, apnea, hypotonia, seizures, resuscitation. 
Figures

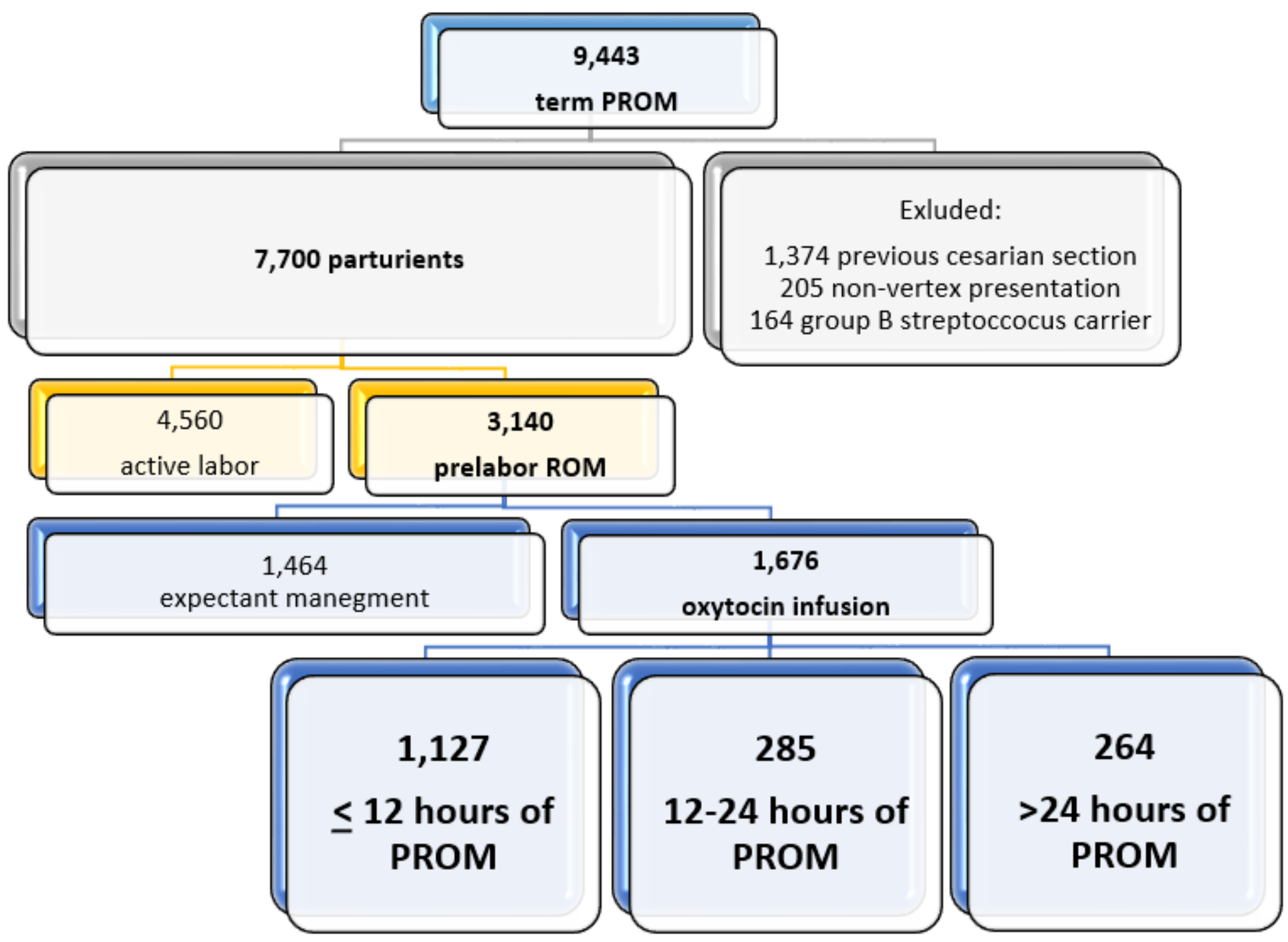

Figure 1

study population 